\title{
Chapter 16 \\ Integration of Catalytic Biofuel \\ Production and Anaerobic Digestion for Biogas Production
}

\author{
G. Hurst, M. Peeters, and S. Tedesco
}

\begin{abstract}
The drive towards a low carbon economy will lead to an increase in new lignocellulosic biorefinery activities. Integration of biorefinery waste products into established bioenergy technologies could lead to synergies for increased bioenergy production. In this study, we show that solid residue from the acid hydrolysis production of levulinic acid, has hydrochar properties and can be utilised as an Anaerobic Digestion (AD) supplement. The addition of $6 \mathrm{~g} / \mathrm{L}$ solid residue to the AD of ammonia inhibited chicken manure improved methane yields by $+14.1 \%$. The co-digestion of biorefinery waste solids and manures could be a promising solution for improving biogas production from animal manures, sustainable waste management method and possible form of carbon sequestration.
\end{abstract}

Keywords Biorefinery · Levulinic acid $\cdot$ Solid residue $\cdot$ Anaerobic digestion • Hydrochar

\subsection{Introduction}

Lignocellulosic biomass is the most abundant renewable feedstock for biofuel production globally [1]. Biorefineries utilise a range of thermochemical processes to produce high platform chemicals for fuels and niche applications. Acid hydrolysis has received significant interest recent years for the valorisation of cellulose and hemi-cellulose fractions of biomass. Acid catalysts such as sulphuric acid $\left(\mathrm{H}_{2} \mathrm{SO}_{4}\right)$ and hydrochloric acid $(\mathrm{HCl})$ under aqueous conditions at mild temperatures $(160$ $250{ }^{\circ} \mathrm{C}$ ) can produce levulinic acid, lactic acid and 5-hydroxymethfural (5-HMF) [2]. Of which levulinic acid has been recognised as one of the most promising precursors for catalytic biofuel production. Several commercial pilot plants by GFBiochemicals

G. Hurst $(\varangle) \cdot$ S. Tedesco

Department of Mechanical Engineering, Manchester Metropolitan University, Dalton Building,

Chester Street, Manchester M1 5GD, UK

e-mail: george.hurst2@stu.mmu.ac.uk

M. Peeters

School of Chemical Engineering, Newcastle University, Newcastle upon Tyne N1 7RU, UK

(C) The Author(s) 2021

I. Mporas et al. (eds.), Energy and Sustainable Futures, Springer Proceedings in Energy,

https://doi.org/10.1007/978-3-030-63916-7_16 
(Caserta, Italy) and Segetis (USA) have demonstrated the potential technologies for the large scale deployment of catalytically produced biofuels [3].

The growth of biorefineries will create challenges to valorise all waste products. Acid catalysis of lignocellulose produces significant amounts of hydrochar-like Solid Residue (SR) material. Recent studies have utilised SR as a solid fuel, pyrolysis feedstock and building material among other applications [4]. Hydrochar has recently been investigated as Anaerobic Digestion (AD) supplement [5]. AD is a sustainable low-cost disposal process for organic matter as well as a source renewable energy in the form of biogas. Biogas is considered an important low-carbon bioenergy source however further implementation is limited due to feedstock constraints. Animal manure is among the most pressing environmental concerns and potential AD feedstock but is limited due to high inhibitor concentrations, most notably ammonium [6]. Recently, hydrochar has been shown to improve biogas yields from swine manure by $32-52 \%$ [7] by adsorbing ammonium, promoting microbial growth and buffering capacity during $\mathrm{AD}$; but is limited due to the high costs associated with hydrochar production.

The pseudo-hydrochar properties of SR from acid catalysis could potentially be used as a low-cost hydrochar for anaerobic digestion supplementation, in order to improve the economics of both levulinic acid production and biogas. In this study, we investigated the feasibility of using SR from the sulphuric acid hydrolysis of Miscanthus $x$ Giganteus to improve the anaerobic digestion of chicken manure.

\subsection{Experimental}

\subsubsection{Solid Residue Preparation and Characterisation}

Miscanthus $x$ Giganteus was dried, ball-milled $(<0.2 \mathrm{~mm})$ and stored in air tight conditions for further use. Solid residue was prepared by heating $0.5 \mathrm{~g}$ of biomass in $10 \mathrm{ml}$ of $2 \mathrm{M} \mathrm{H}_{2} \mathrm{SO}_{4}$ catalyst at $180{ }^{\circ} \mathrm{C}$ for $60 \mathrm{~min}$ under microwave heating. Post reaction the SR was separated, washed with deioinsed water and dried at $60^{\circ} \mathrm{C}$. The post aqueous reaction media was analysed using an HPLC as previously reported [8]. Levulinic acid and SR yields are reported on a dry mass basis and theoretical levulinic acid yield was calculated on structural sugar basis determined according to NREL standard 510-42618. The acid hydrolysis process yielded; $30.8 \mathrm{wt} \%$ SR and 16.7 wt.\% levulinic acid which corresponded to a theoretical $64.5 \%$ levulinic acid yield.

The total solids content and ash content were determined according to standards ASTM D4442 and NREL 42622 respectively. The CHNSO elemental combustion was carried using an Elemental Vario Macro Cube analyser, with oxygen \% calculated by difference. The recalcitrance index, $\mathrm{R}_{50}$, for the $\mathrm{SR}$ was calculated according to Harvey et al. to estimate the carbon sequestration potential [9]. 


\subsubsection{Batch Anaerobic Digestion}

Chicken manure (CM) was collected from a local supplier, dried and stored in a desscitator until use. Inoculum sludge was collected from a local mesophilic AD plant operating at $31{ }^{\circ} \mathrm{C}$. The total volatile solids of $\mathrm{CM}$ and inoculum was set at 8 wt.\% with a $\mathrm{C} / \mathrm{N}$ ratio of 7.1 . The effect of $\mathrm{SR}$ on $\mathrm{AD}$ was investigated by varying the SR concentration by $2-10 \mathrm{~g} / \mathrm{L}$, compared with an un-supplemented control reactor. The biomethane potential assays were conducted in $500 \mathrm{ml}$ glass flasks with working volume of $200 \mathrm{ml}$ and purged with nitrogen gas for $5 \mathrm{~min}$ to achieve anaerobic conditions. The batch reactors were submerged in a water bath maintained at $31 \pm$ $1{ }^{\circ} \mathrm{C}$ and the manually shaken once a day. The batch biomethane potential (BMP) assays were set up in duplicate and operated for 14 days with daily gas measurements. The primary biogas components, $\mathrm{CH}_{4}$ and $\mathrm{CO}_{2}$, were analysed utilising a GeoTech 2000 biogas analyser. The cumulative biogas volumes were then fitted to the modified Gompertz equation shown in Eq. 16.1 [6], using non-linear regression analysis in Matlab@ (2016a).

$$
V_{C H 4}(t)=A_{\text {max }} \exp \left[-\exp \left(\frac{R_{\max } * e}{A_{\max }}(\lambda-t)+1\right)\right]
$$

\subsection{Results}

\subsubsection{Material Characterisation}

The properties of SR, Inoculum and CM are shown in Table 16.1. The SR carbon content exceeded $62 \%$, with a high $\mathrm{H} / \mathrm{C}$ and low $\mathrm{O} / \mathrm{C}$ ratio indicating that the biomass underwent dehydration during the acid hydrolysis process, to produce SR with similar elemental properties to hydrochar. The acid hydrolysis process resulted in a high specific surface area $\left(19 \mathrm{~m}^{2} / \mathrm{g}\right)$ which suggests the SR contains micro-porous structures suitable for adsorption. The $\mathrm{pH}$ of $\mathrm{SR}$ was measured in water at 1:10 mass ratio and the solid residue was slightly acidic and could negatively affect buffering capacity of $\mathrm{AD}$. The recalcitrance index, $\mathrm{R}_{50}$, is a measurement of char stability to microbial degradation and suitability for carbon sequestration. The SR had a $\mathrm{R}_{50}$ of 0.66 which is comparable with that of biochar and indicates the land application of post-digestion SR could be a potential form of stable carbon sequestration. 
Table 16.1 Characteristics of inoculum, chicken manure (CM) and SR

\begin{tabular}{l|l|l|l|l}
\hline & Raw-Miscanthus & SR & Inoculum & CM \\
\hline TS $(\%, w . b)$ & 97.2 & 95.15 & 7.6 & 87.7 \\
\hline VS $(\%, w . b)$ & 94.4 & 92.4 & 5.5 & 64.7 \\
\hline VS $(\%$, d.b $)$ & 97.37 & 97.37 & 72.1 & 73.7 \\
\hline $\mathrm{pH}$ & 3.56 & 2.5 & 7.78 & N/A \\
\hline $\mathrm{BET}\left(\mathrm{m}^{2} / \mathrm{g}\right)$ & $\mathrm{N} / \mathrm{A}$ & 19 & N/A & N/A \\
\hline $\mathrm{C}(\%$, DS basis $)$ & $48.1 \%$ & $62.4 \%$ & 32.1 & 34.7 \\
\hline $\mathrm{H}(\%$, DS basis $)$ & $6.0 \%$ & $5.5 \%$ & 4.7 & 5.2 \\
\hline $\mathrm{N}(\%$, DS basis $)$ & $0.5 \%$ & $0.3 \%$ & 7.2 & 7.7 \\
\hline $\mathrm{S}(\%$, DS basis $)$ & $0.1 \%$ & $0.4 \%$ & 0.9 & 0.8 \\
\hline $\mathrm{O}(\%$, DS basis $)$ & $42.4 \%$ & $23.8 \%$ & 27.1 & 23.8 \\
\hline $\mathrm{O} / \mathrm{C}$ & N/A & 0.29 & N/A & N/A \\
\hline $\mathrm{H} / \mathrm{C}$ & N/A & 1.06 & N/A & N/A \\
\hline $\mathrm{R}_{50}$ & N/A & 0.66 & N/A & N/A \\
\hline
\end{tabular}

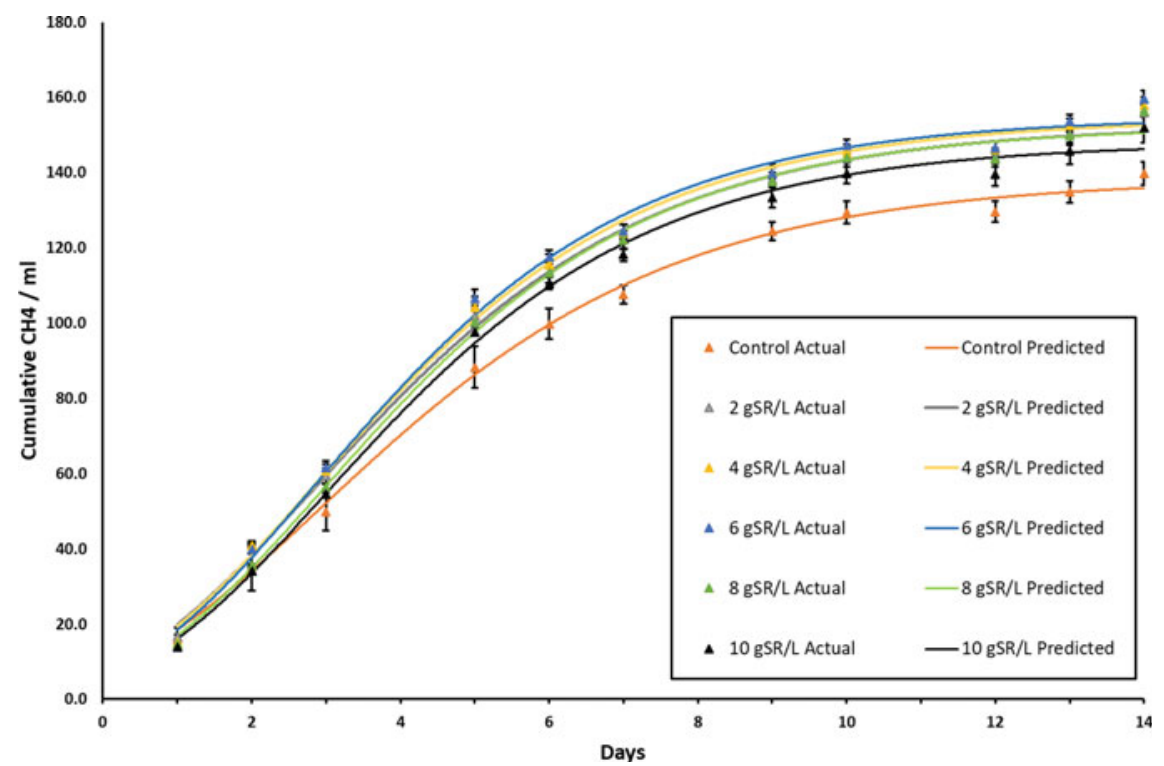

Fig. 16.1 Cumulative methane yield with varying SR addition and predicted yields 


\subsubsection{Effects of SR on Methane Production During CM Digestion}

Figure 16.1, shows the cumulative methane yields from the AD of CM over 14 days, alongside the predicted methane yields according to Eq. 16.1. The control reactor yielded $136 \mathrm{ml} \mathrm{CH}_{4} / \mathrm{gVS}$ compared with the $\mathrm{CM}$ stoichiometric $\mathrm{CH}_{4}$ potential of $286 \mathrm{ml} / \mathrm{gVS}$, which corresponds with a biodegradability index of $48 \%$. The addition of $2 \mathrm{gSR} / \mathrm{L}$ increased the methane yield $\left(+12 \% \mathrm{CH}_{4}\right)$ with respect to the $\mathrm{CM}$ control, strongly indicating a beneficial effect to $\mathrm{AD}$, by either promoting microbial growth or adsorbing inhibitors. There was only a minor improvement with increasing SR concentration at $6 \mathrm{~g} / \mathrm{L}\left(+14.1 \% \mathrm{CH}_{4}\right)$ suggesting that the $\mathrm{SR}$ is not being degraded in the reactors. The minor improvement also indicates that the AD system is not undergoing significant stress and the positive effects of SR could potentially be more significant in more toxin-rich environments. There was a noticeable decrease in $\mathrm{CH}_{4}$ yields at higher SR loads ( 8 and $10 \mathrm{gSR} / \mathrm{L}$ ), which can be attributed to the potential toxicity of SR on AD microorganisms. However, for all BMP conditions, SR addition resulted in higher methane yield than the $\mathrm{CM}$ control, which emphasises the positive effects on biogas production.

The Gompertz model has successfully been used to model BMP experiments from a range of substrates [6, 10]. For all experimental conditions in this study, the regression values exceeded 0.99 , indicating a good fit of the model parameters shown in Table 16.2. The addition of SR increased the maximum methane production $\left(\mathrm{A}_{\max }\right)$ by $6.9-11.8 \%$ and the maximum methane production rate $\left(\mathrm{R}_{\max }\right)$ by $18.3-$ $25.9 \%$, compared with the control reactor. This suggests that SR increased both the biodegradability of CM over 14 days and also the maximum microbial activity. The lag time of microbial AD system is associated with the maximum degradation rate and the adaption of the microbial community to the reaction conditions. Table 16.2, shows that SR concentrations prolonged the lag phase compared with the control

Table 16.2 Summary of Kinetic data for the AD of CM with different SR concentrations

\begin{tabular}{l|l|l|l|l|l|l}
\hline \multirow{2}{*}{ Condition } & Cumulative $\mathrm{CH}_{4}$ yield & \multicolumn{4}{|l|}{ Modified Gompertz parameter } & \multicolumn{2}{l}{ Statistics } \\
\cline { 2 - 7 } & $F$ & $A_{\operatorname{Max}}$ & $R_{\text {Max }}$ & $\lambda$ & $R^{2}$ & $p$ \\
\hline Control & $140 \pm 3$ & 138.4 & 18.44 & 0.1696 & 0.9960 & 0.9976 \\
\hline $2 \mathrm{~g} / \mathrm{L}$ & $156 \pm 2$ & 152.7 & 21.7 & 0.256 & 0.9946 & 0.9966 \\
\hline $4 \mathrm{~g} / \mathrm{L}$ & $158 \pm 2$ & 154.4 & 22.51 & 0.3189 & 0.9937 & 0.9942 \\
\hline $6 \mathrm{~g} / \mathrm{L}$ & $160 \pm 1$ & 154.8 & 23.22 & 0.3974 & 0.9917 & 0.9939 \\
\hline $8 \mathrm{~g} / \mathrm{L}$ & $157 \pm 1$ & 152.4 & 22.32 & 0.4615 & 0.9949 & 0.9960 \\
\hline $10 \mathrm{~g} / \mathrm{L}$ & $152 \pm 3$ & 148.0 & 21.81 & 0.492 & 0.9945 & 0.9963 \\
\hline
\end{tabular}

$F$ is the measured cumulative methane production, $\mathrm{mL} / \mathrm{gVS}$ added, $\mathrm{A}_{\max }$ is the predicted cumulative methane production, $\mathrm{mL} / \mathrm{gVS}$ added day, $\mathrm{R}_{\mathrm{Max}}$ is the maximum methane production rate, $\mathrm{mL} / \mathrm{gVS}$ day, and $\lambda$ is the duration of the lag phase, days 
reactor from 0.17 to 0.49 days. The increase in lag time implies a mild microbial inhibition with increasing SR concentrations and that the microbial community reacted negatively to those $\mathrm{SR}$ levels. This can be further seen with a decrease in $\mathrm{A}_{\max }$ from 154.8 to $148.0 \mathrm{ml} \mathrm{CH}_{4} / \mathrm{gVS}$ day between 6 and $10 \mathrm{~g} / \mathrm{L}$ suggesting that inhibition is caused from the SR itself and not from imbalances in the complex system. The negative effects of SR on AD must be further investigated, but does not negate the potential benefits.

\subsection{Conclusion}

In this study, the addition of SR from acid hydrolysis improved the methane yields, by $6.9-14.1 \%$. During the mesophilic anaerobic digestion of CM. The SR from a high yielding levulinic acid process was determined to have hydrochar properties which were evident during the AD process. The modified Gompertz model suggested that SR increased both the microbial degradation rate and the cumulative methane yields, however toxicity was a factor at higher concentrations. The integration of $\mathrm{AD}$ into acid hydrolysis biorefineries could potentially create synergies for the dual production of biofuel and biogas.

Acknowledgements This research was supported by Manchester Metropolitan University via the Research Accelerator Award (RAG 2017/18-113380). BBSRC NIBB's network High Value from Plants funded the training and compositional analysis of biomass in conjunction with Celignis ltd. (CORE-TA-19).

\section{References}

1. S. Takkellapati, T. Li, M.A. Gonzalez, An overview of biorefinery-derived platform chemicals from a cellulose and hemicellulose biorefinery. Clean Technol. Environ. Policy 20(7), 1615$1630(2018)$

2. A. Mukherjee, M.J. Dumont, V. Raghavan, Review: sustainable production of hydroxymethylfurfural and levulinic acid: challenges and opportunities. Biomass Bioenerg. 72, 143-183 (2015)

3. F.D. Pileidis, M.M. Titirici, Levulinic acid biorefineries: new challenges for efficient utilization of biomass. ChemSusChem 9(6), 562-582 (2016)

4. S. Kang, J. Fu, G. Zhang, From lignocellulosic biomass to levulinic acid: a review on acidcatalyzed hydrolysis. Renew. Sustain. Energy Rev. 94, 340-362 (2018)

5. W. Guo, Y. Li, K. Zhao, Q. Xu, H. Jiang, H. Zhou (2019) Performance and microbial community analysis of anaerobic digestion of vinegar residue with adding of acetylene black or hydrochar. Waste and Biomass Valoriz., no. 0123456789

6. G.K. Kafle, L. Chen, Comparison on batch anaerobic digestion of five different livestock manures and prediction of biochemical methane potential (BMP) using different statistical models. Waste Manag. 48, 492-502 (2016)

7. H. Jin et al., Hydrochar derived from anaerobic solid digestates of swine manure and rice straw: a potential recyclable material. BioResources 13(1), 1019-1034 (2018) 
8. G. Hurst, I. Brangheli, M. Peeters, S. Tedesco, Solid residue and by-product yields from acidcatalysed conversion of poplar wood to levulinic acid. Chem. Pap. 74(5), 1647-1661 (2020)

9. O.R. Harvey, L.J. Kuo, A.R. Zimmerman, P. Louchouarn, J.E. Amonette, B.E. Herbert, An index-based approach to assessing recalcitrance and soil carbon sequestration potential of engineered black carbons (biochars). Environ. Sci. Technol. 46(3), 1415-1421 (2012)

10. J. Pan, J. Ma, X. Liu, L. Zhai, X. Ouyang, H. Liu, Effects of different types of biochar on the anaerobic digestion of chicken manure. Bioresour. Technol. 275, 258-265 (2019)

Open Access This chapter is licensed under the terms of the Creative Commons Attribution 4.0 International License (http://creativecommons.org/licenses/by/4.0/), which permits use, sharing, adaptation, distribution and reproduction in any medium or format, as long as you give appropriate credit to the original author(s) and the source, provide a link to the Creative Commons license and indicate if changes were made.

The images or other third party material in this chapter are included in the chapter's Creative Commons license, unless indicated otherwise in a credit line to the material. If material is not included in the chapter's Creative Commons license and your intended use is not permitted by statutory regulation or exceeds the permitted use, you will need to obtain permission directly from the copyright holder. 